\title{
Examining students' perceptions of innovation and entrepreneurship in physics
}

\author{
Anne E. Leak, ${ }^{1}$ Christian Cammarota, ${ }^{1}$ Nathan Cawley, ${ }^{1}$ and Benjamin Zwickl ${ }^{1}$ \\ ${ }^{1}$ School of Physics and Astronomy, Rochester Institute of Technology, 84 Lomb Memorial Drive, Rochester, NY 14623
}

\begin{abstract}
The joint AAPT and APS PHYS21 report emphasizes preparing students for diverse career paths, including the need for more opportunities to learn innovation and entrepreneurship in physics. To support these changes, research is needed on students' interest and perceptions of innovation and entrepreneurship, and suggestions for integration into the undergraduate physics experience. We conducted semi-structured focus groups with 20 physics majors around several concepts related to innovation and entrepreneurship: technology, creativity, design, business, communication, and leadership. Emergent and thematic coding was used to analyze students' responses. Students have a complex view of innovation and entrepreneurship in physics perceiving creativity as closely related to physics, especially in undergraduate research, while business and leadership skills were distinct from physics and closer to engineering. These findings have implications for understanding students' perceptions of physics as a disciplinary community and field of study, and can assist departments seeking to better support students' careers.
\end{abstract}

\section{INTRODUCTION}

Despite many successful efforts to improve students' persistence in physics and other STEM fields, poor retention at colleges and universities remains a challenge [1]. While retention is a complex issue with many factors, some studies have found that departments with a strong focus on career preparation (including resume-writing, job applications, and access to alumni networks) are better able to recruit and retain physics majors than those without such a focus [2]. Yet, preparing physics students for careers is complex and means going beyond measures that support students to pursue academic research careers. In fact, of the nearly 7,500 physics bachelor's degrees from 2013-14 who were surveyed a year after graduating by the American Institute of Physics (AIP), approximately $40 \%$ entered the workforce with half of these in the private sector [3, 4].

Since physics majors often pursue careers in the private sector, AAPT and APS in the Joint Task Force on Undergraduate Physics Programs (J-TUPP) examined the needs and current preparation for such pursuits. Their study found that “...physics bachelor's degree recipients working in the private sector reported a desire for more programming skill development, more experience in industrial and applied physics environments, and a better understanding of the marketability of their degree [5]." Overall, their findings emphasize a strong need to develop and support opportunities for learning innovation and entrepreneurship (I\&E) skills in order to better prepare physics majors for their future careers [5].

The NSF-funded PIPELINE Network hopes to support the development of physics innovation and entrepreneurship education through institutional engagement. This project recognizes that with such support, physics students should be better prepared to connect their technical, conceptual, laboratory, and problem solving skills from physics to private sector applications that highlight creativity, technology, business and other career-related aspects. Making physics more relevant to students' future careers will increase their marketability as well as add to the career-focus preparation that has been shown to improve retention.

Of paramount concern of the PER community is how to facilitate institutional and department change to support research-based educational practices. While there are a myriad of challenges to effectively doing so, PER and research on institutional change have identified several approaches to minimize or overcome challenges (e.g., [6, 7]). In their research on transforming departmental culture to encourage educational innovation, Corbo and colleagues suggest that efforts be 1) coordinated across three levels of the university including faculty, department, and administration, and 2) grounded in multiple research-supported change perspectives including scientific management, evolutionary, social cognition, cultural, political, and institutional literature [8]. From these perspectives, their framework considers influencing change by attending to behavior incentives, holistic system views, decision-making, and the underlying culture of the department among others. While PER and department change initiatives tend to focus on faculty-centered culture, culture is strongly shaped by students. Students become members of a department culture over time by participating as members and in turn, shape the values and expectations of that culture [11]. In our study, we apply a culture-change framework and propose an additional level of the change focused on students.

To integrate innovation and entrepreneurship (I\&E) in physics, we need to understand and relate these concepts to students' existing perceptions. With this goal in mind, we posed the following questions: (1) What aspects of I\&E do physics students value as integral to the physics curriculum? and (2) What expectations do physics students have for learning I\&E?

\section{METHODOLOGY}

To examine students' perspectives of innovation and entrepreneurship (I\&E) in physics, we conducted six semistructured focus groups with 20 undergraduate physics majors at a university in Western New York. Participants were 
recruited randomly in the last month of the Spring semester from across all physics majors, while insuring that students from each grade were represented. We elected to do focus groups, rather than individual interviews, since these were best suited to determine pervasive values and perspectives across the department and most feasible given the scope and timeline of our study.

Each focus group interview was about an hour long and was designed to facilitate discussion around six aspects of I\&E based on the PHYS21 report [5], Epicenter's Engineering Majors Survey [9, 12], informal conversations with faculty and students, and discussions with the PIPELINE network. Specifically, interviews were divided into discussions on contextual background information, experiences with $I \& E$, and $I \& E$ values as related to physics. For context, we asked students to discuss their majors/minors (other than physics), career plans, and courses that have been valuable toward these goals. To understand their perspectives of I\&E, such as communication for example, we asked students to describe 1) what aspects of communication they have learned as part of the physics program (or in other courses outside of physics) and 2) should they learn communication as a physics major. While we had tentative definitions in mind, we focused on exploring the operational definitions of these concepts from students' own perspectives and only provided prompting when necessary to initiate discussions.

Interviews were transcribed and coded using NVIVO qualitative analysis software. We applied an ethnographic domain analysis coding scheme based on the work of Spradley that allowed us to explore students' constructed meanings for cover terms based on six aspects of I\&E as well as the relationship of these terms with physics [13]. Since we selected the aspects of innovation and entrepreneurship a priori, focusing on the relationships between these terms and physics as discussed in focus groups provided a systematic method for understanding the cultural meanings that students' applied to I\&E.

\section{FINDINGS}

This paper explores the ways in which innovation and entrepreneurship (I\&E) are valued in physics. Our findings are organized by six aspects of I\&E. From the domain analysis of each aspect, we focus on three commonly discussed relations to physics. Table I shows each aspect and the three relations. These are then expanded on in the text below to highlight both students values and their expectations for physics departments.

Creativity. When defining creativity, students typically defined this aspect as applying knowledge they already have in order to solve more advanced problems. One student said, "You have to be creative in a way...kind of see how the different equations can come together to find an answer." This comes through when thinking of creativity's relation to coursework in physics. The student went on to mention that
TABLE I. Student perceptions of innovation and entrepreneurship (I\&E) in physics using domain analysis where each I\&E aspect is linked by the relation terms to physics

\begin{tabular}{|c|c|}
\hline I\&E Aspect & Relation to physics \\
\hline \multirow[t]{3}{*}{ Creativity } & is beneficial to physics students \\
\hline & is present in physics coursework \\
\hline & is present in physics labs and research \\
\hline \multirow[t]{3}{*}{ Communication } & $\begin{array}{l}\text { is important for interdisciplinary work and working } \\
\text { with other physicists }\end{array}$ \\
\hline & $\begin{array}{l}\text { is important for presentations and writing papers in } \\
\text { physics }\end{array}$ \\
\hline & is important to physics but learned elsewhere \\
\hline \multirow[t]{3}{*}{ Technology } & $\begin{array}{l}\text { is important to physics students when focused on } \\
\text { computers and software }\end{array}$ \\
\hline & should be available to physics students, but optional \\
\hline & is more of an engineering aspect than physics \\
\hline \multirow[t]{3}{*}{ Leadership } & is important for group work in physics \\
\hline & $\begin{array}{l}\text { is important to learn for any career path for physics } \\
\text { students and others }\end{array}$ \\
\hline & is not important to physics \\
\hline \multirow[t]{3}{*}{ Design } & is more engineering than physics \\
\hline & should be available to physics but optional \\
\hline & is important to lab work and physics careers \\
\hline \multirow[t]{3}{*}{ Business } & is important to grant funding in physics \\
\hline & should be available to physics students, but optional \\
\hline & is not important to physics \\
\hline
\end{tabular}

putting equations together in such a way is like solving a puzzle, and the student is figuring out how to solve the problem. The students focused on more than just creativity in coursework. They also believe that creativity is a necessary part of conducting research. "Yeah. I know creativity is needed for research. And if you're working with professors on research, you're building up all these new ways to attack an actual unknown problem." The students make the same relation about using what they already know about physics in a new way. Additionally, participants mentioned that using creativity to figure things out on their own and being given the freedom to figure things out on their own would help them in the future.

Communication Students defined communication as being able to share ideas with each other verbally in a group setting, as a presentation, and as written work such as papers. The students emphasized the importance of communication and broke it down into two separate categories, communication through working together and communication when presenting work. Students believed that communication was key to working together on homework assignments. Some students utilized a shared physics workspace when completing assignments where they could find other students doing the same problems and work together. Others emphasized the need for communication in upper-division courses where it was a necessary part of doing homework with peers. 
When it came to presenting work, students focused on writing ability and presentation skills. In one case, students related the ability to communicate through writing by to research when they said, "You've got to be able to share your findings with people. And you have to be able to share your findings accurately too. You've got to be able to write it." Others considered a wider range of career paths in physics stating that, "I think that's just a big part of any job or anything. You're probably going to have to give a presentation at some point." Presentation skills are a vital part of communication, but students differed on whether or not this aspect is important to physics specifically, or a broader skill necessary for any future career.

Technology According to students, technology encompassed any kind of hands-on experience in lab work or experimental work, as well as working with computer software and computer coding. The students agreed that technology was important to physics, but also felt that the subject should be optional since many students would not want to work with technology in their undergraduate physics courses or in their careers. Describing technology's importance, one student said, "Knowing how to use a computer and how a computer actually works is a really useful thing to know. And then also the other side...if you get some crap piece of hardware, [you can] figure out how it works if you know technology." These applications were valuable to most students. Students typically agreed that more technology-based coursework would increase their skill set for a job in industry. However, others reflected that even though technology is important to some, it is not important to all undergraduate physics majors. They felt that technology-related courses should be available, but optional, since some students would never need the hands-on aspects of physics. This same reasoning was seen in students reflection that technology was more of an aspect of engineering than of physics. A few students argued that "if you wanted to learn more about things like that you would get an electrical engineering degree, or a mechanical engineering degree to learn more about the devices." Overall, students felt that hands-on technology experiences should be optional, while technology related to computer work in physics is essential.

Leadership Students defined leadership as the ability to lead or train a group of people, though, there was no clear consensus among the students with respect to leadership's importance in physics. Some students saw the importance of leadership for group work or for working within hierarchies, while others felt as though leadership had no place within the major. The students who felt that leadership was important in physics pointed out large group projects, such as CERN, and the large numbers of physicists those projects employ. In addition to physics research groups, students brought up the importance of leadership in the workplace. Some thought that "knowing how to lead a group, [and] knowing how to respond to a leader in a group is what you would do in your job no matter what you're going to go into." This broad view of leadership represents the view that this aspect is important to all physics majors. The reflection on responding to a leader also relates back to the ability to communicate and collaborate in group settings. There were a number of students, though, who said that they have never felt the need for leadership in physics. Overall, students seemed to differ on their perceptions of leadership and it's importance to physics.

Design Students defined design in physics as figuring out how to fix something or coming up with a solution to a problem relating to device creation and improvement. However, they seemed to struggle with relating design to physics without prompting from the interviewer. From their coconstructed definition during interviews, design was classified as more of an engineering practice than a physics practice. Students went as far as saying that they wanted to be distinguished from engineers. When it came to fixing equipment in lab, one student even suggested that they would just call an engineer to fix it, saying, "It's like if an instrument breaks...you can call up an engineer. It's their job to fix these kind of things." Others seemed to think that design courses should be available for physics students who wanted to learn these practices. They surmised that students who wanted to go into industry after college would want some sort of experience with design software and practices so they could be more prepared for their job. Even where students did want to learn more about design, they focused on design from a computer or software perspective. "I feel like it would be useful to have design software experience." In only one instance, did students seem to more broadly apply the term by saying, "you have to design your solution... when you examine a problem. You have to be able to know where to go...draw a diagram...see what is going on." Most students who thought there should be options to learn design felt as though it would be important to future careers in industry, but not necessarily relevant to all physics majors.

Business Students defined business in physics as starting or working in a business, or applying for grants. The students seemed to agree that when it comes to applying for funding, business was important to physics. One student said directly that they "think it would be helpful knowing like how to deal with writing a grant proposal." This same notion came up multiple times. When expanding on starting or working in businesses though, students felt this was unimportant to physics. One student said, "I feel there are ways you can apply business, but I don't think it's really core physics." This statement, though denouncing business as not a part of physics, leads into another theme discussed about this aspect: business skills should be optional for physics majors. Students seemed to think that business was another track or minor that certain physics majors may want to pursue and that the resources to succeed should be available to them outside the physics department.

\section{CONCLUSIONS}

Our findings show that while physics undergraduates perceive creativity and communication as essential to physics, 
technology and design are seen as more engineering, and leadership and business are different entirely. These aspects of $I \& E$ in physics differ from the way engineers describe them. For engineers, innovation means finding creative designs for specific goals using a variety of hands-on technology and tools [9]. Additionally, Epicenter's research findings show that entrepreneurship in science and engineering stems from business while referring to customers, markets, and ventures [9]. For physics students, innovation is more about developing creative ideas or solutions to problems often using computer-based software technology. Entrepreneurship is typically research-centered to focus on grant funding, presentations to demonstrate findings, and collaborating with teams. While our study is limited in scope to a small sample of majors in one department, we plan to scale our work by interviewing undergraduates at other institutions and using results to develop a national survey. This study, and such future research, will contribute to our understanding of how physics majors think about innovation and entrepreneurship as they relate to their field of study.

Understanding students' values and expectations about innovation and entrepreneurship has implications for initiating department change. A culture change framework suggests that attending to the underlying culture at multiple institutional levels leads to successful transformation [8]. Students are a key part of department culture, so their interpretation of proposed changes can influence acceptance or rejection of implemented solutions. Students, as members of a culture, develop common ways of thinking, knowing, and doing physics [11]. Over time, students understand what it means to be part of a physics department by becoming part of this social group. For example, our findings suggest that physics students do not see design as part of the culture of doing physics. Therefore, adding design courses or design-based projects might be perceived as separate from learning physics and not valued. Furthermore, though physics majors often pursue jobs in engineering industries, the culture of physics may make aspects of that work seem less relevant even when we know that many physics majors will work in these types of careers. Knowing physics majors and the meaning they apply to cultural changes being initiated will allow departments to better facilitate changes, support a broader range of potential career paths, and encourage new cultural perceptions that can make department initiatives more successful.

\section{ACKNOWLEDGMENTS}

We would like to thank the PIPELINE Network and the physics students who volunteered to participate in this study. This work is supported by the National Science Foundation's Improving Undergraduate STEM Education (IUSE) program under Award No. 1624882.
[1] X. Chen, "STEM Attrition: College Students' Paths Into and Out of STEM Field," National Center for Education Statistics, Institute of Education Sciences, U.S. Department of Education, Washington, DC, (NCES 2014-001, 2013).

[2] R. Hilborn, R. Howes, and K. Drane, "Strategic Programs for Innovations in Undergraduate Physics: Project Report," The American Association of Physics Teachers, College Park, MD, (January 2003).

[3] P. Mulvey and J. Pold, Physics Bachelor's Initial Employment, Tech. Rep. (American Institute of Physics, 2015).

[4] S. Nicholson and P. Mulvey, "Roster of Physics Department with Enrollment and Degree Data," (2008).

[5] P. Heron and L. McNeil (Co-chairs), "Phys21:Preparing Physics Students for 21st-Century Careers," (American Physical Society, 2016).

[6] M. Dancy, C. Henderson, and C. Turpen, How faculty learn about and implement research-based instructional strategies: The case of peer instruction, Phys. Rev. Phys. Educ. Res., 12, 010110 (2016).

[7] C. Henderson, M. Dancy, and M. Niewiadomska-Bugaj, Use of research-based instructional strategies in introductory physics: Where do faculty leave the innovation-decision process?, Phys. Rev. Phys. Educ. Res., 8, 020104 (2012).
[8] J. C. Corbo, D. L. Reinholz, M. H. Dancy, S. Deetz, and N. Finkelstein, Framework for transforming departmental culture to support educational innovation, Phys. Rev. Phys. Educ. Res., 12, 010113 (2016).

[9] A. R. Peterfreund, E. Costache, H. L. Chen, S. K. Gilmartin, S. Sheppard, Infusing innovation and entrepreneurship into engineering education: Looking for change as seen by ASEE members, 2012 to 2015, ASEE's 123rd Annual Conference and Exposition (New Orlands, 2016).

[10] T. Byers, T. Seelig, S. Sheppard, and P. Weilerstein, Entrepreneurship: Its role in engineering education, In The Bridge, National Academy of Engineering, 43, 2 (2013).

[11] E. C. Collins and J. L. Green, Learning in classroom settings: Making or breaking a culture, In K. T. Clift and C. M. Evertson (Eds.) Focal points: Qualitative inquiries into teaching and teacher education, Teacher Education Monograph: No. 12, (Washington, DC: ERIC Clearinghouse on Teacher Education, 1992).

[12] Engineering Majors Survey, Epicenter National Center for Engineering Pathways to Innovation, Accessed on July 1, 2017 at http://epicenter.stanford.edu/page/engineering-majorssurvey (2015).

[13] J. P. Spradley, J. P. Participant Observation. San Francisco: Holt, Rinehart and Winston (1980). 